\title{
Gormund e Isembart, a cura di Andrea Ghidoni
}

\section{Giuseppe Noto}

\section{(2) OpenEdition}

\section{Journals}

\section{Edizione digitale}

URL: http://journals.openedition.org/studifrancesi/316

DOI: 10.4000/studifrancesi.316

ISSN: 2421-5856

\section{Editore}

Rosenberg \& Sellier

\section{Edizione cartacea}

Data di pubblicazione: 1 aprile 2015

Paginazione: 121

ISSN: 0039-2944

\section{Notizia bibliografica digitale}

Giuseppe Noto, « Gormund e Isembart, a cura di Andrea Ghidoni », Studi Francesi [Online], 175 (LIX | I) | 2015, online dal 01 avril 2015, consultato il 18 septembre 2020. URL : http://journals.openedition.org/ studifrancesi/316 ; DOI : https://doi.org/10.4000/studifrancesi.316

\section{Questo documento è stato generato automaticamente il 18 settembre 2020.}

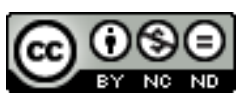

Studi Francesi è distribuita con Licenza Creative Commons Attribuzione - Non commerciale - Non opere derivate 4.0 Internazionale. 


\title{
Gormund e Isembart, a cura di Andrea Ghidoni
}

\author{
Giuseppe Noto
}

\section{NOTIZIA}

Gormund e Isembart, a cura di Andrea GHIDONI, Alessandria, Edizioni dell’Orso, 2013 («Gli

Orsatti. Testi per un Altro Medioevo», 36), pp. 175.

1 Il breve frammento (661 versi) della canzone di gesta conosciuta per abitudine editoriale come Gormund et Isembart va collocato (stando al ragionamento sviluppato nell'«Introduzione» dal curatore) tra il 1060 e il 1088: quanto basta per farne, se non la più antica canzone di gesta che conosciamo (è quasi contemporanea alla Chanson de Roland), sicuramente uno dei più antichi (e ancor imperfetti) esemplari delle caratteristiche costitutive del genere epico antico-francese e dal punto di vista formale e dal punto di vista dei contenuti (la guerra e il mondo carolingio), così come si svilupperanno nei due secoli successivi.

2 Al netto della coloritura linguistica anglonormanna dell'unico testimone (il manoscritto II 181 allocato presso la Bibliothèque Royale de Belgique di Bruxelles), la provenienza linguistica dell'autore è da collocarsi a parere del curatore nel sud-ovest. Tale autore narra della morte eroica di Gormund e Isembart alla testa di un esercito saraceno vòlto alla conquista della Francia di re Ludovico: come Ghidoni mostra con chiarezza, si tratta di una narrazione scopertamente fondata su eventi storici reali e in particolare sulle razzie vichinghe che, nel corso del IX secolo, colpirono sia le zone costiere della Francia sia (attraverso il corso dei fiumi) le regioni interne.

3 Il lacerto era già stato in passato più volte pubblicato (in ultimo da Bruno Panvini, Gormond et Isembart, Parma, Pratiche, 1990), ma questa edizione curata da Alessandro GHIDONI (che nasce da una tesi di dottorato discussa nel 2013 presso l'Università di Macerata) pare finalmente ben contemperare, da una parte, il criterio di conservatività rispetto al testo manoscritto e, dall'altra, il dovere del filologo di avanzare ipotesi 
ricostruttive (in questo caso in relazione all'«ipotetico antigrafo del manoscritto» medesimo, p. 45), attraverso princìpi di edizione e criteri di trascrizione decisamente funzionali; così come funzionali appaiono sia l'impostazione dell'apparato in due fasce (una per le lezioni del manoscritto rigettate; l'altra per le note di carattere variamente ecdotico, esegetico, linguistico o letterario) sia l'impaginazione, con il testo originale a sinistra e la traduzione (ad un tempo aderente all'originale e scorrevole) a fronte.

Chiudono il volume due accurate «Appendici» dedicate a «La lingua del poema» e alla «Versificazione».

5 Si tratta di un lavoro ben condotto e capace di rispondere alle esigenze sia dello specialista di letteratura in lingua d'oil sia del lettore colto interessato all'epica anticofrancese. Spiace soltanto constatare qualche indulgenza di troppo a registri formali colloquiali (ad esempio a p. 12 il pronome «lui» da riferirsi, a quel che intendo, a «un poema») e un tono a tratti a mio avviso eccessivamente baldanzoso nei confronti delle mende dei Maestri del passato (Bruno Panvini è, ad esempio, accusato di «errori “maccheronici"» a p. 42).

6 Esaustiva e ben organizzata la bibliografia esibita nelle note e al fondo del volume. 